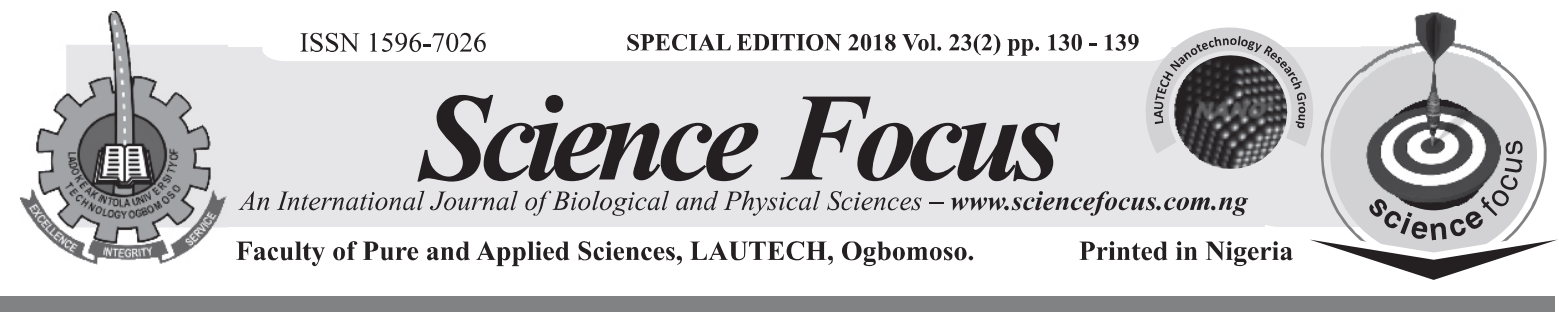

https://doi.org/10.36293/sfj.2019.0014

\title{
ANTIMICROBIAL ACTIVITIES OF ALLIUM CEPA-MEDIATED SILVER NANOPARTICLES AGAINST SOME CLINICAL BACTERIAL ISOLATES
}

\author{
Senbadejo, T.Y*, Ganiyu, O.T and Muhammad, A.B \\ Department of Biological Sciences, College of Natural and Applied Sciences, Fountain University, \\ Osogbo, Osun State, Nigeria.
}

\begin{abstract}
The synthesis of nanoparticles is a research area that is growing as a result of the potential applications for the development of new ideas and novel technologies. This study revealed the convenient, fast and economic method to synthesize silver nanoparticles (AgNPs) using onion (Allium cepa) bulb extract. Onion bulbs were obtained from the open market in Osogbo, Osun State. The characterization of the synthesized AgNPs was done using UV-vis spectroscopy, Fourier-transform infrared spectroscopy (FTIR) and scanning electron microscopy (SEM). The antimicrobial effect of synthesized silver nanoparticles using aqueous, methanolic and fresh extract of Allium cepa were assessed using clinical isolates of Staphylococcus aureus and Escherichia coli by agar well diffusion method. It was observed that the crude extract + silver nitrate solution changed from light yellow to dark brown in colour after incubation in the dark for $3 \mathrm{~h}$. The mixture of onion extract and silver nitrate solution produced particles with maximum absorbance at the wavelength of $535 \mathrm{~nm}$ using $U V$ vis spectroscopy. The FTIR spectra revealed that many of the functional groups obtained using crude plant extract were repeated in FTIR spectrum of AgNPs with some changes in how they are positioned and also in the absorption bonds intensity. The particles were spherical in shape. From the experiment, the AgNPs was observed to have antimicrobial potentials as it inhibited the growth of Staphylococcus aureus and Escherichia coli with zones of inhibition ranging from 18-26 $\mathrm{mm}$ at concentration of $125 \mu \mathrm{g} / \mathrm{ml}$.
\end{abstract}

Keywords: Allium cepa, Silver nanoparticles, Staphylococcus aureus, Escherichia coli

*Corresponding author email: tosinoble@yahoo.com

\section{Introduction}

Onion (Allium cepa) which can also be called 'garden onion or 'bulb' onion belongs to the family Alliaceae. It is known in history as one of the oldest cultivated vegetables, and the bulbs have been used as a food source for a long period of time. The bulbs are large, fleshy and firm with leaves bluish-green and hollow (Azu et al., 2006). The three common varieties of onions are available in red, white and purple skinned (Wang et al., 2009).
Onions which are easily propagated, transported and stored are known to be effective against several infections and diseases including common cold, heart disease, diabetes, coughs and sore throat (Augusti, 2008). They can also be bacteriostatic in nature (Saulis et al., 2002). Certain chemical compounds that have anti-inflammatory, anticancer and antioxidant properties such as quercetin are believed to be present in onions (Wilson and Demmings-Adams, 2007). The outer layer of the flesh has higher concentration of flavonoids compared with 
other part of the onions (Nemeth and Piskula, 2007). Onions are also known to contain high polyphenols than other Allium vegetables (Wang et al., 2009).

Nanoparticles are particles that range from $1-100 \mathrm{~nm}$ in size. Silver nanoparticles have attracted attention and become researchers' focus due to a wide variety of potentials in applicable areas like catalysis, optics, antimicrobials, biomedical and electronic fields (Abdullah and Hamud, 2013; Awwad et al., 2013). AgNPs can be synthesized using methods like thermal decomposition, chemical and photochemical reactions in reverse micelles, electrochemical, sonochemical and also by biological methods (Nethradevi et al., 2012).

Biological methods that require bioderived chemicals, bacteria, fungus and plant extracts are considered safe and economically sound for the fabrication of nanomaterial among other methods (Mason et al., 2012; Abdullah and Hamud, 2013). Green synthesis of AgNPs has become a better alternative to conventional physical and chemical methods which require the use of chemical compounds or organic solvents as reducing agents, not environmental friendly and also expensive (Mason et al., 2012). A range of various plant parts including the leaf, flower, seed, tuber and bark extracts have been investigated for their ability to synthesize silver nitrate efficiently.

Bioreduction of $\mathrm{Ag}^{+}$ions to yield silver nanoparticles are caused by combinations of biomolecules such as vitamins, enzymes/proteins, organic acids such as citrates, amino acids, and polysaccharides found in the extracts (Abdullah and Hamud, 2013). Silver has effective inhibition on microbes in medical and industrial processes. One of the most important applications of silver and silver nanoparticles in medical industry is topical ointments which can be used to prevent infection against open wounds and burn (Ip et al., 2006).

Several reports have studied antimicrobial activity of AgNPs synthesized using chemical and biological processes. This study is aimed at investigating the phytochemical composition of Allium cepa and to biosynthesize AgNPs using aqueous and methanolic extract of Allium cepa. The AgNPs was characterized and the antimicrobial activities of extracts and biosynthesized AgNPs were compared against clinical pathogens.

\section{Materials and Methods}

\section{Collection of Plant Samples}

The sample (Allium cepa) was obtained from Oja-oba market in Osogbo, Osun state.

\section{Preparation of Aqueous Extract of Allium cepa}

Allium cepa extraction was carried out thus: The onion was washed with sterile distilled water and kept at room temperature to air dry for some minutes before the outer covering of the onion was peeled manually. Exactly $200 \mathrm{~g}$ of onion was blended and soaked in $200 \mathrm{ml}$ of distilled water for $24 \mathrm{~h}$. The pulp obtained after blending was shaken vigorously in a sterile glass container for enhancement of proper extraction; it was then filtered using sterile cotton cloth after which the extract was obtained. The extract obtained was stored in a bottle below ambient temperature (Trease and Evans, 2009).

\section{Methanolic Extraction of Allium cepa}

Onion bulb was weighed; $200 \mathrm{~g}$ of it was blended and soaked in $200 \mathrm{ml}$ of methanol for $24 \mathrm{~h}$. The pulp obtained after blending was shaken vigorously in a sterile glass 
container for enhancement of proper extraction. It was filtered using a filter paper and funnel. The extract obtained was stored in a bottle below ambient temperature (Trease and Evans, 2009).

\section{Fresh Extraction of Allium cepa}

Onion bulb was weighed and $200 \mathrm{~g}$ of it was blended, the pulp obtained was filtered using a sterile filter paper and the extract obtained was stored in a bottle below ambient temperature (Trease and Evans, 2009).

\section{Phytochemical Screening}

The extract of onion (Allium cepa) were subjected to phytochemical screening to determine the presence of saponin, carbohydrate, cardiac glycoside, tannins, flavonoids, alkaloid and steroid (Obadoni and Ochuko, 2001; Trease and Evans, 2009).

\section{Synthesis and Characterization of Silver Nanoparticles}

For biosynthesis of nanoparticles, $5 \mathrm{ml}$ of aqueous, methanolic and fresh extracts of A. cepa were added to $10 \mathrm{ml}$ of $1 \mathrm{mM}$ silver nitrate and was incubated in the dark for about $3 \mathrm{~h}$ (Saxena et al., 2010). It was observed for color change. The synthesized AgNPs were characterized using UV-vis spectroscopy for the verification of reduction of $\mathrm{AgNO}_{3}$ to $\mathrm{Ag}^{+}$ by the onion extract. The Fouriertransform infrared spectroscopy (FTIR) analysis of the extracellular biosynthesized AgNPs was done. Scanning electron microscope (SEM) was used to observe the shape of synthesized nanoparticles.

\section{Antimicrobial Activity}

The antimicrobial property of the Allium cepa extract and the synthesized AgNPs was determined using agar well diffusion method, against some clinical isolates of Escherichia coli and Staphylococcus aureus. The test pathogens were collected from University of Ilorin Teaching Hospital (UITH), Ilorin. The isolates were sub-cultured on nutrient agar plates and incubated for $24 \mathrm{~h}$. Pure colonies were picked and stored in slants for further use.

\section{Results}

\section{Phytochemical Profile of Onion Extract}

Table 1 shows the phytochemical profile of aqueous and methanolic extracts of onion. Saponin, carbohydrate, cardiac glycoside, tannins, flavonoids and alkaloids were present in both aqueous and methanolic extracts.

\section{Synthesis of AgNPs}

There was a change in colour during the incubation of the extract and $\mathrm{AgNO}_{3}$, from pale yellow to dark brown due to reduction of silver ions. The brown colour stabilized after the incubation. Plate 1 shows colour change before and after synthesis of AgNPs.

\section{Characterization of AgNPs}

UV-visible spectrophotometer was used to measure the maximum absorbance produced during reduction of $\mathrm{AgNO}_{3}$ to $\mathrm{Ag}^{+}$by the onion extract. As shown in Figure $1 \mathrm{UV}$-vis absorption spectrum of the produced AgNPs showed the peak maxima at $535.00 \mathrm{~nm}$ due to excitation of surface plasmon vibrations in nanoparticles. This is characteristic of silver nanoparticles and the peak indicated that the synthesized nanoparticles were dispersed in the aqueous solution with no evidence of aggregation. 
Table 1: Phytochemical profile of Allium cepa extracts

\begin{tabular}{lllcc}
\hline S/N & Constituents & Tests & Aqueous & Methanolic \\
\hline 1 & Carbohydrates & Reducing sugar & +++ & ++ \\
& & Molisch & + & + \\
2 & Cardiac glycosides & Keller-Kiliani & ++ & +++ \\
3 & Saponin & Frothing & + & + \\
& & Foaming & + & ++ \\
4 & Triterpene/steroids & Lieberman Bucchard & + & ++ \\
5 & Tannins & Ferric Chloride & + & + \\
& & Lead sub-acetate & + & ++ \\
6 & Flavonoids & Sodium Hydroxide & ++ & - \\
7 & Alkaloids & Dragendorff & + & + \\
& & Wagners & + & + \\
\hline
\end{tabular}

+++, Present in high concentration; ++, moderately present; +, present; -, absent

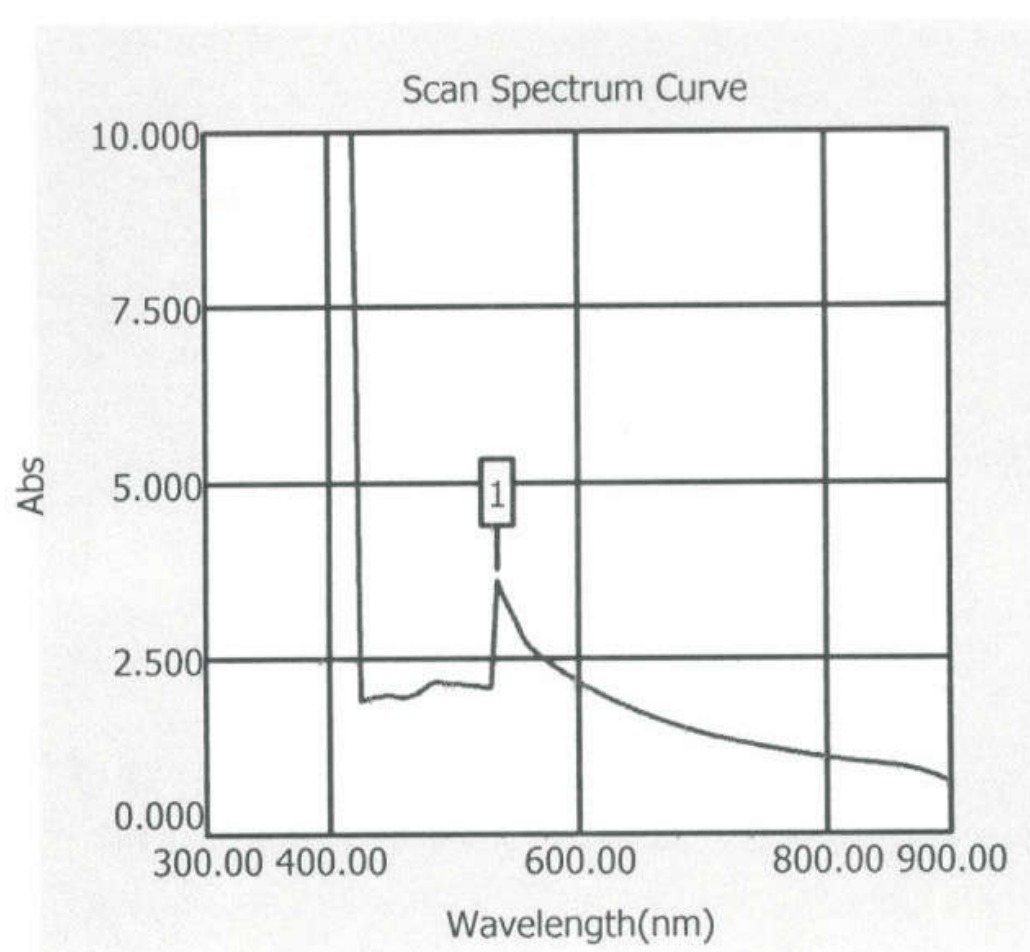

Figure 1: UV-vis spectrum of fresh silver nanoparticles

\section{FTIR Spectroscopic Analysis}

FTIR analysis was carried out to identify the possible biomolecules in onion extract responsible for capping leading to efficient stabilization of the AgNPs and to determine the chemical functional groups in the sample. The observation confirms the infrared fingerprints spectroscopy spectrum of the AgNPs as the absorption band located at $1661.7 \mathrm{~cm}^{-1}$, which may be as result of $\mathrm{C}=\mathrm{O}$ or $\mathrm{C}=\mathrm{C}$ stretching vibration. For the higher wave numbers, the peak at $1356.5 \mathrm{~cm}^{-1}$ is due to $\mathrm{C}-\mathrm{N}$ or $\mathrm{C}$ $\mathrm{O}$ stretching of proteins and $\mathrm{O}-\mathrm{H}$ stretching of carbohydrates and water, the bands at both 800.6 and $876.7 \mathrm{~cm}^{-1}$ were assigned to the left-handed helix DNA. 
After synthesis, the absorption peaks at 2607, 2371 and $1865 \mathrm{~cm}^{-1}$ corresponding to $\mathrm{CH}_{3}$ and $\mathrm{CO}$ observed in plant extract get narrower and shifted to higher frequency regions, while those at 3539, 3255 and $3209 \mathrm{~cm}^{-1}$ corresponding to $\mathrm{NH}$

Manual Peak Pick Results

\begin{tabular}{|l|l|}
\hline Sample Filename & Aqueous Extract.spc \\
\hline File Title & $11 / 15 / 2018$ 10:09:48 title \\
\hline Date & Thu Nov 15 10:18:14 2018 \\
\hline
\end{tabular}

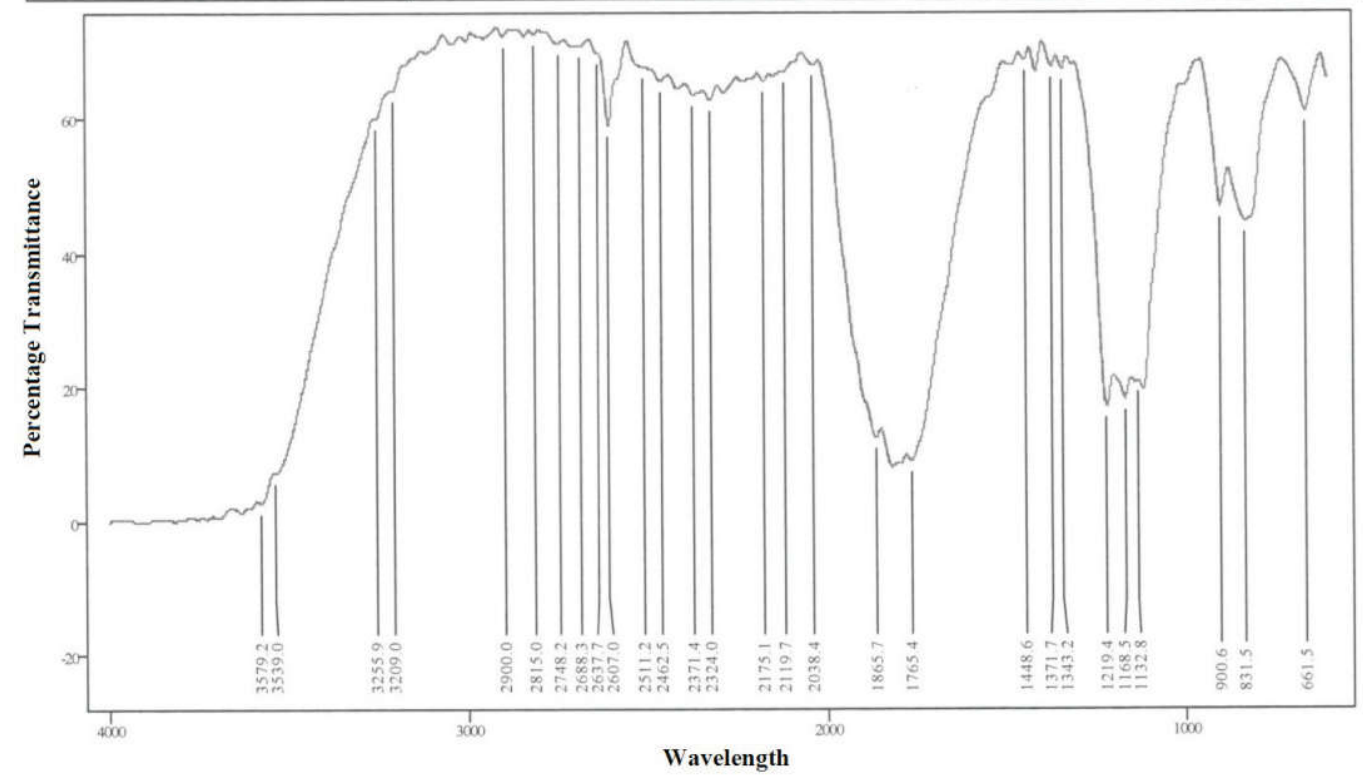

Figure 2: FTIR spectra of aqueous extract

Manual Peak Pick Results

\begin{tabular}{|l|l|}
\hline Sample Filename & Aqueous AgN03.spc \\
\hline File Title & $11 / 15 / 2018$ 10:00:21 title \\
\hline Date & Thu Nov 15 10:04:48 2018 \\
\hline
\end{tabular}

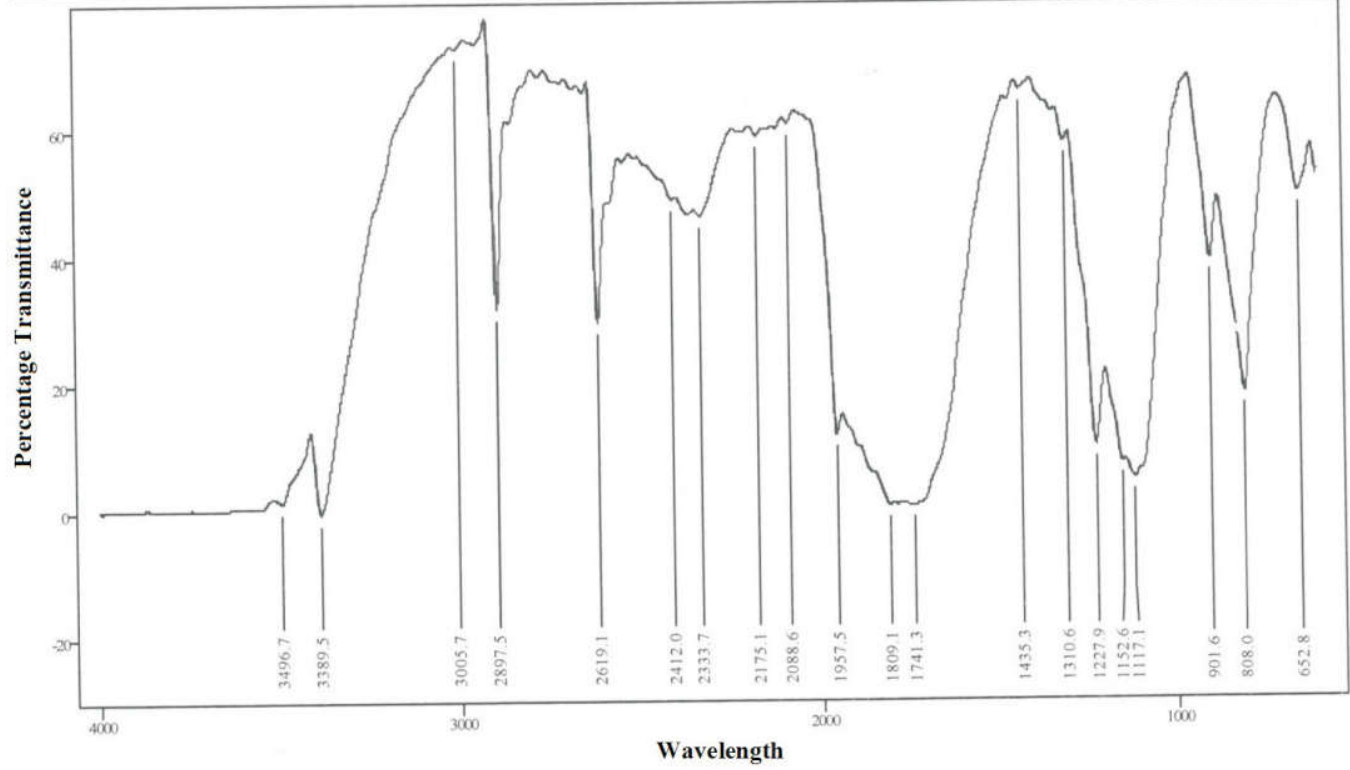

Figure 3: FTIR spectra of AgNPs 
and $\mathrm{OH}$ decreased in intensity and shifted to low frequency regions (Figures 2 and 3 ).

\section{Antimicrobial Analysis}

The growth of Staphylococcus aureus and Escherichia coli was inhibited by the extract at $100 \mu \mathrm{g} / \mathrm{ml}$. All the AgNPs have antimicrobial properties as they inhibited the growth of the organisms at $125 \mu \mathrm{g} / \mathrm{ml}$. The synthesized nanoparticles using fresh extract showed the highest zone of inhibition with $26 \mathrm{~mm}$ against $E$. coli and $24 \mathrm{~mm}$ against $S$. aureus as shown in Table 2. Methanolic extract-mediated AgNPs had zones of inhibition of $20 \mathrm{~mm}$ on E. coli and $18 \mathrm{~mm}$ on $S$. aureus and aqueous extract-mediated AgNPs yielded zones of inhibition of $20 \mathrm{~mm}$ on $E$. coli and $18 \mathrm{~mm}$ on $S$. aureus (Table 2). Some selected groups of Gram positive and negative antibiotics were used as positive control. Ofloxacin had no inhibition against the test organisms, while gentamycin, ciprofloxacin and amoxicillin inhibited the growth of the test organisms with higher zones of inhibition (Table 2).

\section{Discussion}

The phytochemical screening of Allium cepa in this study has shown the presence of flavonoids, tannins and other chemical constituents which explains why they are known to have antibacterial, antitoxigenic, and anticarcinogenic properties. Flavonoids were reported to be present in both aqueous and methanolic extract in the study as reported by Geetha et al. (2011). Flavonoids are known to be good antimicrobial agent over a wide range of microorganisms which may be due to the ability of flavonoids to form complexes with extracellular soluble proteins and bacteria cell walls. The reduction of silver ions to silver using green synthesis was monitored by measuring the UV-vis spectrum of the reaction mixture. After the sample was observed under the UV-vis spectrophotometer for its maximum absorbance and wavelength, the maximum peak was found to be at $535 \mathrm{~nm}$ for onion extract-mediated AgNPs.

The FTIR spectra showed that many peaks obtained using crude plant extract were repeated in FTIR spectrum of AgNPs with changes in the intensity of absorption bonds and position. The band at $813 \mathrm{~cm}^{-}$ ${ }^{1}$ reflects structural information about polyphenols caused by ring $\mathrm{CH}$ deformation (Nethradevi et al., 2012). These are as a result of compound such as flavonoids, alkaloid, terpenoids and tannin present in onion plant. The biological components are known to interact with metal salts via the functional group and mediate their reduction to nanoparticles (Nethradevi et al., 2012).

The structural changes indicated that the reduction and the stabilization of silver nanoparticles increase through these groups. This is related to changes reported by Abboud et al. (2013). The bands obtained between 3579 and $3209 \mathrm{~cm}^{-1}$ and 1865 and $1448 \mathrm{~cm}^{-1}$ in the AgNPs spectra correspond to the amide groups. Amide groups are the most important band for protein infrared spectrum which confirms that the phytoconstituents of plant (mostly protein) interact with silver nanoparticles (Abboud et al., 2013; Lu et al., 2011; Adebayo-Tayo et al., 2016). This suggested that AgNPs synthesized from onion extract were surrounded by some protein bands through either free amine groups or cysteine residues which makes stabilization of AgNPs by coating of protein possible (Figure 3)

Scanning electron microscopy (SEM) is used to observe the size distribution and morphologies of the synthesized AgNPs. The AgNPs synthesized using onion extract were scanned by SEM. It reveals that silver nanoparticles seemed to be 


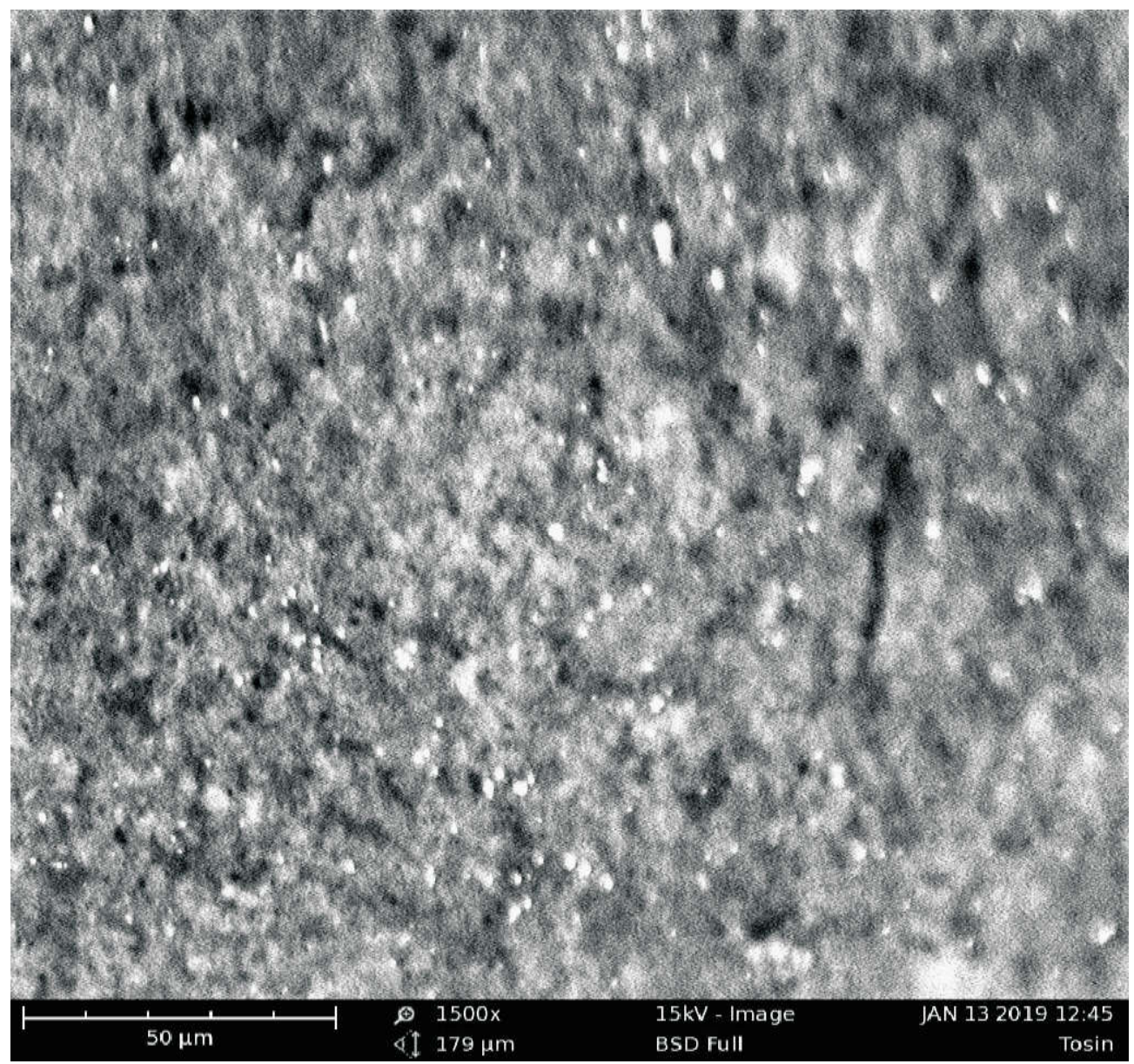

Figure 4: SEM micrographs of AgNPs using onion extract

crystalline in form. The present study has shown that onion extract has the potential to reduce silver nitrate ions into AgNPs.

The result of this study revealed that the fresh, aqueous and methanolic extracts of Allium cepa had antimicrobial activity when the extracts were tested against $S$. aureus and $E$. coli. The clinical pathogens used in this study were more susceptible to the extract than silver nitrate, and higher zone of inhibition was observed for biosynthesized AgNPs, which agrees with the study of Azu et al. (2006) that reported antimicrobial activity of Allium cepa extracts on $S$. aureus, $P$. aeruginosa, Streptococcus pneumoniae, and E. coli. According to research carried out by
Gomaa et al. (2017), AgNPs formed by extract of Allium cepa had highest inhibitory effect which ranged from 27 to $29 \mathrm{~mm}$ on $P$. aeruginosa and Bacillus subtilis. In this study, the biosynthesized nanoparticles had activities on the clinical isolates which ranged from 18 to $26 \mathrm{~mm}$ in diameter, while the extracts had inhibitions of 7-14 $\mathrm{mm}$. Some of the test pathogens which were susceptible to ciprofloxacin which is a broad spectrum antibiotic were also susceptible to the biosynthesized AgNPs. This shows that medicinal plant extracts and their AgNPs can also exhibit broad spectrum activities as reported by Adebayo-Tayo et al. (2016). 


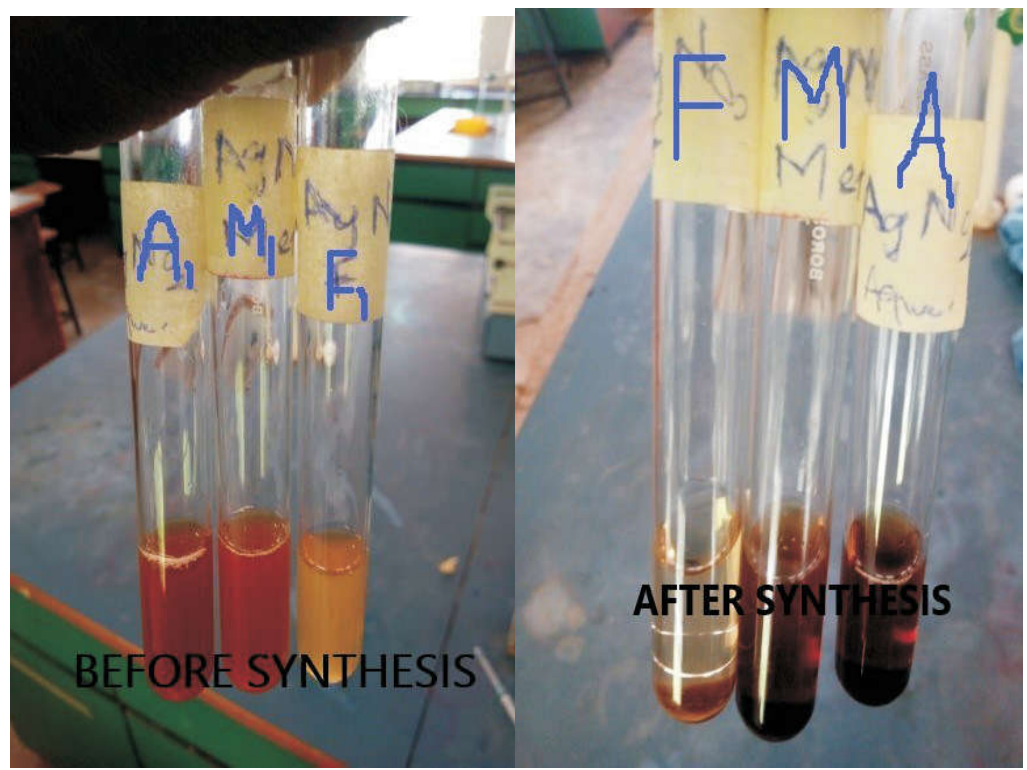

Plate 1: Before and after synthesis of $\mathrm{AgNO}_{3}$ using fresh (F), aqueous (A) and methanolic $(\mathrm{M})$ extracts of onion

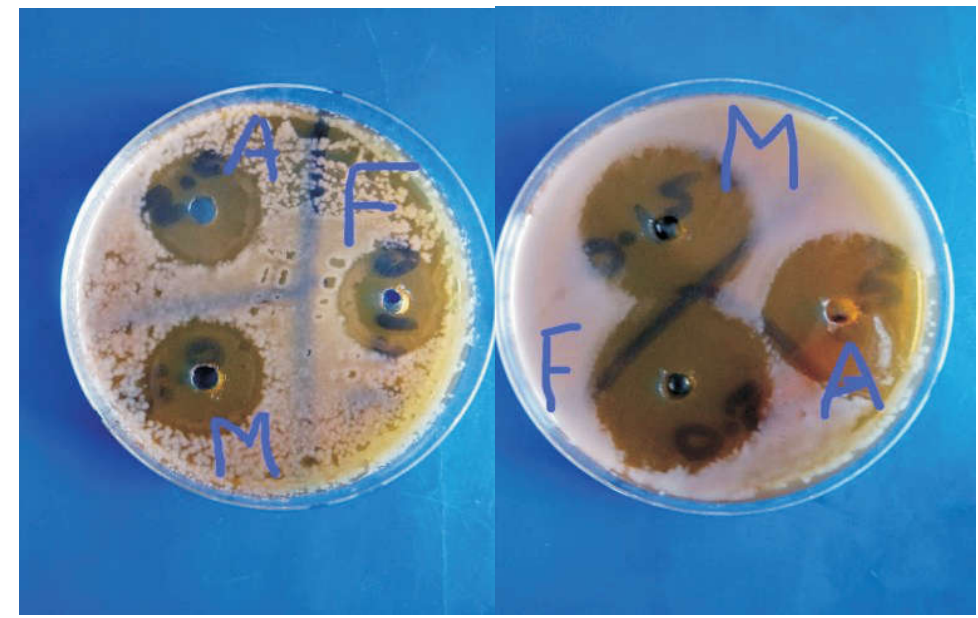

Plate 2: Antimicrobial activities of AgNPs (A, aqueous; F, fresh; M, methanolic extract) on $S$. aureus (Left) and E. coli (Right)

The results obtained shown that Allium cepa is a potent medicinal plant as the juice extract contains biologically active substances that contribute to the antimicrobial characteristics of the plant.

\section{Conclusion}

This research has clearly demonstrated the antimicrobial potentials of Allium cepa and validates the antimicrobial properties of its fresh, aqueous and methanolic extracts. The study also showed that onion extract has the potential to reduce silver nitrate ions into AgNPs. Further, AgNPs synthesized from Allium cepa possessed good antimicrobial activity and thus may serve as an alternative against the conventional antibiotics and drugs.

\section{Disclosure of Funding}

This research did not receive any special grant from any funding agencies in the public, commercial or not for-profit-sector

\section{Conflict of Interest}

Authors declare no conflict of interest 
Table 2: Antimicrobial activities of the extracts and biosynthesized AgNPs from Allium cepa against the test pathogens

\begin{tabular}{llllllllll}
\hline \multicolumn{1}{c}{ Pathogens } & Allium cepa & \multicolumn{1}{c}{ Control } \\
& $\begin{array}{l}\text { Fresh } \\
\text { extract } \\
(\mathrm{mm})\end{array}$ & $\begin{array}{l}\text { Fresh } \\
\text { extract } \\
+\end{array}$ & $\begin{array}{l}\text { Aqueous } \\
\text { extract } \\
\text { AgNPs } \\
(\mathrm{mm})\end{array}$ & $\begin{array}{l}\text { AgNPs } \\
(\mathrm{mm})\end{array}$ & $\begin{array}{l}\text { Methanolic } \\
\text { extract } \\
\text { AgNPs } \\
(\mathrm{mm})\end{array}$ \\
$\mathrm{AgNO}_{3}$ & Gen & Cip & Amo Ofl \\
\hline S. aureus & 14 & 24 & 20 & 18 & 10 & 33 & 32 & 28 & - \\
E. coli & 10 & 26 & 18 & 20 & 6 & 32 & 30 & 20 & - \\
\hline
\end{tabular}

Each value is an average of three readings

\section{References}

Abboud, Y., Eddahbi, A., El Bouari, A., Brouzi, K., Aitenneite, H. and Mouslim, J. 2013. Microwave-assisted approach for rapid and green photosynthesis of silver nanoparticles using aqueous onion (Allium сера) extract and their antibacterial activity. Journal of Nanostructure in Chemistry 3: 84.

Abdullah, A.A. and Hamid, Z.U. 2013. Antimicrobial activity of silver nanoparticles from Capsicum sp. against Staphylococcus sp., Bacillus sp., Pseudomonas sp. and Escherichia coli. Journal of Biology, Agriculture and Healthcare 3(7): 67-72.

Adebayo-Tayo, B.C., Akinsete, T.O. and Odeniyi, O.A. 2016. Phytochemical composition and comparative evaluation of antimicrobial activities of juice extract of Citrus aurantifolia and its silver nanoparticles. Nigeria Journal of Pharmaceutical Research 12(1): 59-67.

Augusti, K. 2008. Therapeutic values of onion (Allium cepa) and garlic (Allium sativum). Indian Journal of Experimental of Biology 34: 634-640.
Awwad, A.M., Salem, N.M. and Abdeen, A. O. 2013. Green synthesis of silver nanoparticles using carob leaf extract and its antibacterial activity. International Journal of Industrial Chemistry 4(29): 1-6.

Azu, N.C., Onyeagba, R.A., Nworie, O. and Kalu, J. 2006. Antibacterial Activity of Allium cepa (onions) and Zingiber officinale (Ginger) on Staphylococcus aureus and Pseudomonas aeruginosa isolated from high vaginal swab. The Internet Journal of Tropical Medicine 3 (2): 2 .

Geetha, M., Ponmohzi, M., Saravanakumar, M. and Suganyadevi, P. 2011. Extraction of anthocyanin and analyzing its antioxidant properties from different onion (Allium cepa) varieties. International Journal of Research in Pharmaceutical Sciences 2(3): 497-506.

Gomaa, E.Z. 2017. Antimicrobial, antioxidant and antitumor activities of silver nanoparticles synthesized by Allium cepa extract: A green approach. Journal of Genetic Engineering and Biotechnology 15(1): 49-57.

Ip, M., Lui, S. L., Poon, V. K., Lung, M. I. and Burd, A. 2006. Antimicrobial activities of silver dressings: an in-vitro 
comparison. Journal of Medical Microbiology 55: 59.

Mason, C., Vivekanandhan, S., Misra, M. and Mohanty, A.K. 2012. Witch grass (Panicum virgatum) extract mediated green synthesis of silver nanoparticles. World Journal of Nanoscience and Engineering 2: 47-52.

Nemeth, K. and Piskula, M.K. 2007. Food content, processing, absorption and metabolism of onion flavonoids, International Journal of Industrial Chemistry 47(4): 397-409.

Nethradevi, C., Sivakumar, P. and Renganathan, S. 2012. Green synthesis of silver nanoparticles using Datura metel flower extract and evaluation of their antimicrobial activity. International Journal of Nanomaterials and Biostructures 2(2): 16-21.

Obadoni, B.O. and Ochuko, P.O. 2001. Phytochemical studies and cooperative efficacy of the crude extract of some homeostatic plant in Edo and Delta State of Nigeria. Journal of Pure and Applied Sciences 8: 203-208.
Saulis, A.S., Mogford, J.H. and Mustoe, T.A. 2002. Effect of mederma on hypertrophic scarring in the rabbit ear model. Plastic Reconstructive Surgery 110(1): 177-183.

Saxena, A., Tripathi, R.M. and Singh, R.P. 2010. Biological synthesis of silver nanoparticles by using onion (Allium cepa) extract and their antibacterial activity. Digest Journal of Nanomaterials and Biostructures 5(2): 427- 432.

Trease, G.E. and Evans, W.C. 2009. Pharmacognosy. $16^{\text {th }}$ edition. Published by William Evans.

Wang, L., Lee, I.M. and Zhang, S.M. 2009. Dietary intake of selected flavonoids, flavones, and flavonoid rich foods and risk of cancer in middle aged and older women. American Journal Nutrition 89(3): 90-91.

Wilson, E.A. and Demming-Adams, B. 2007.Antioxidant, anti-inflammatory and antimicrobial properties of garlic and onions. Nutrition and Food Science 37(3): 178-183 